\title{
Real-life effectiveness of ICS/LABA inhalers in asthma: The evidence generated and future needs for optimal patient management
}

\author{
Konstantinos Kostikas ${ }^{1,2,3}$
}

The fixed-dose combinations (FDC) of inhaled corticosteroids (ICS) with longacting $\beta 2$-agonists ( $L A B A$ ) represent one of the most widely used controller options for the management of patients with asthma, worldwide. Recently, the Global Initiative for Asthma (GINA) reports recommended the use of ICScontaining regimens in all the steps of asthma management, suggesting that the preferred reliever option would be combinations of ICS/formoterol, setting consequently these inhalers as the preferred controller option for such patients ${ }^{1}$. In the quest of the selection of the appropriate inhaled medication for our patients with asthma, a broad choice of inhalers is currently available. The treating physician needs to take into consideration several characteristics of the inhalation device, involving both the substances included but also the characteristics of the device that will be most appropriate for the individual patient, in order to ensure the acceptability of the device by the patient that will consequently lead to better adherence to the inhaled treatment and better disease outcomes ${ }^{2}$. The 'ideal' inhaler should carry several properties, including being user- and environmental-friendly (e.g. being breath-actuated, being multi-dose and portable yet robust, avoiding harmful additives, e.g. propellants), allowing for control of the appropriate dosing by providing feedback and dose receipt confirmation, providing the dosing independently of environmental conditions and inspiratory flow rate, and achieving high lung deposition with high respirable fine particle fraction ${ }^{3}$. In the journey of the management of patients with airways disease, the treating physicians should be familiar with the properties of the inhalation devices that they prescribe, choose the appropriate device based on the characteristics of each individual patient, involve actively the patients in the device and treatment selection, evaluate the patients' inhalation technique and train them appropriately at each visit, and re-evaluate the need for a different device whenever they identify a potential gap in the use of the previous one, but switch to a new device only with the patients' involvement and appropriate education ${ }^{4}$.

The dry powder inhaler (DPI) combination of budesonide and formoterol in the Elpenhaler ${ }^{\circledR}$ has been shown to be bioequivalent in terms of lung deposition to the same formulation delivered by the Turbuhaler ${ }^{\circledR}$ device in a crossover pharmacokinetic study in 100 patients with asthma ${ }^{5}$. Moreover, there is evidence of high satisfaction and acceptability of the Elpenhaler ${ }^{\circledR}$ in patients with asthma and COPD using the Feeling of Satisfaction with Inhaler (FSI-10) questionnaire that was comparable or better to other DPI devices ${ }^{6,7}$, whereas it also presented lower rates of critical errors that affect drug delivery to the lungs when compared with the Diskus ${ }^{\circledR}$ and Turbuhaler ${ }^{\circledR}$ devices in a prospective study of 755 patients with asthma and COPD ${ }^{8}$.

In this issue of Pneumon, Bakakos et al. ${ }^{9}$ provide further clinically relevant information on the real-life effectiveness of the ICS/LABA combination of budesonide/formoterol in the Elpenhaler ${ }^{\circledR}$ device in patients with asthma, by presenting the results of the BOREAS study. This is a 6 -month prospective multicenter observational study that enrolled 1230 asthma patients who were prescribed either of the two doses of Elpenhaler ${ }^{\circledR}$ budesonide/ formoterol (200/6 or 400/12 $\mu \mathrm{g})$. The authors were able to show significant

\author{
AFFILIATION \\ 1 Respiratory Medicine Department, Medical \\ School, University of loannina, loannina, \\ Greece \\ 2 Respiratory Medicine Department, \\ University Hospital of Ioannina, Ioannina, \\ Greece \\ 3 Respiratory Medicine, Observational and \\ Pragmatic Research Institute, Singapore, \\ Singapore
}

\section{CORRESPONDENCE TO}

Konstantinos Kostikas. Respiratory Medicine Department, Medical School, University of Ioannina, 45110, Ioannina, Greece. E-mail: ktkostikas@gmail.com

ORCID ID: https://orcid.org/0000-00030774-3942

\section{KEYWORDS}

editorial, pulmonology, respiratory medicine, inhalers, asthma

Received: 3 December 2021

Accepted: 6 December 2021 
improvements in the asthma control questionnaire (ACQ-7, that was the primary endpoint of the study) and the mini asthma quality of life questionnaire (Mini AQLQ) at 3 months that were sustained at 6 months. Interestingly, the mean improvements in both these patient-reported outcomes exceeded the minimal clinically important difference (MCID) of 0.5 points ${ }^{10,11}$. These improvements were evident in patients with higher and lower blood eosinophils (using the 150 cells/ $\mu \mathrm{L}$ as cut-off point), as well as in patients with and without metabolic and psychiatric comorbidities. These results are accompanied by significant improvements in lung function, with an acceptable safety profile of the two doses of budesonide/formoterol. These improvements in asthma control, health status and lung function, are likely attributed to the fact that in more than $50 \%$ of the patients, the new treatment was a step-up from previous treatments, whereas $41 \%$ were treatment-naive prior to the study enrollment. These results further support the clinical effectiveness of the FDC of budesonide/formoterol in the Elpenhaler ${ }^{\circledR}$ device, when prescribed as step-up or initial treatment in patients with asthma in real-life practice in various clinical settings. The study results are limited by the pre-post openlabel design that did not involve a control group and the fact that the treating physicians made the conscious decision to provide these treatment options in patients with uncontrolled asthma (the baseline ACQ-7 value was 2.18, well-above the 1.5 cut-off point for uncontrolled asthma for this tool) as a step-up or initial treatment. Based on the study design, a significant placebo effect cannot be ruled out, however, the accompanying improvement in lung function (e.g. >200 $\mathrm{mL}$ in mean $\mathrm{FEV}_{1}$ ) further supports the clinically relevant effectiveness of these treatments.

External validity is critical for the generalization of the efficacy observed in randomized placebo-controlled appropriately blinded trials. This is important in asthma, a disease entity with significant variability in the course of time. As an example, in a study of patients of the Wessex Severe Asthma Cohort, less than 25\% of patients with severe eosinophilic asthma would have been eligible in the phase III licensing trials of interleukin- 5 biologics, due to their stringent inclusion criteria ${ }^{12}$. Therefore, we need real-life studies with broader inclusion criteria that engage patients with various characteristics that would have excluded them from the typical randomized controlled trials of asthma. The BOREAS study included $36.3 \%$ of current or ex-smokers, while it evaluated the effectiveness of the specific budesonide/formoterol combination in patients with various comorbidities, with consistent results. The absence of a placebo arm is partly compensated by the fact that the authors collected both subjective (ACQ-7 and MiniAQLQ) and objective (lung function) measures of effectiveness, and thus they need to be commended for this selection of outcomes. In a previous well-designed study in patients with asthma, placebo inhalers and sham acupuncture improved symptoms, but lung function was improved only by active bronchodilator (albuterol) ${ }^{13}$. In open-label studies of inhaled medication, the inclusion of patient-reported and objective outcomes is necessary, and the authors of the BOREAS study are to be commended for their selection. The study also confirms previous data by reporting high patient satisfaction by the Elpenhaler ${ }^{\circledR}$ device, as well as the favorable safety profile of the budesonide/formoterol combination in patients with asthma. Future data generation could focus on the use of the budesonide/formoterol FDC in the Elpenhaler ${ }^{\circledR}$ device as maintenance and reliever therapy (MART), as proposed for the ICS/formoterol combinations in current asthma recommendations ${ }^{1}$.

\section{CONFLICTS OF INTEREST}

The author has completed and submitted the ICMJE Form for Disclosure of Potential Conflicts of Interest and none was reported. K. Kostikas declares that he is the Editor-in-Chief of the journal Pneumon.

\section{FUNDING}

There was no source of funding for this research.

\section{ETHICAL APPROVAL AND INFORMED CONSENT}

Ethical approval and informed consent were not required for this study.

\section{DATA AVAILABILITY}

Data sharing is not applicable to this article as no new data were created.

\section{PROVENANCE AND PEER REVIEW}

Commissioned; internally peer reviewed.

\section{REFERENCES}

1. Global Initiative for Asthma. 2021 GINA Main Report. June 1, 2016. Accessed July 24, 2021. https://ginasthma.org/ gina-reports/

2. Usmani OS. Choosing the right inhaler for your asthma or COPD patient. Ther Clin Risk Manag. 2019;15:461-472. doi:10.2147/TCRM.S160365

3. Vincken W, Dekhuijzen PR, Barnes P. The ADMIT series - Issues in inhalation therapy. 4) How to choose inhaler devices for the treatment of COPD. Prim Care Respir J. 2010;19(1):10-20. doi:10.4104/pcrj.2009.00062

4. Laube BL, Janssens HM, de Jongh FHC, et al. What the pulmonary specialist should know about the new inhalation therapies. Eur Respir J. 2011;37(6):1308-1331. doi:10.1183/09031936.00166410

5. Grekas N, Athanassiou K, Papataxiarchou K, Rizea Savu S, Silvestro L. Pharmacokinetic study for the establishment of bioequivalence of two inhalation treatments containing budesonide plus formoterol. J Pharm Pharmacol. 2014;66(12):1677-1685. doi:10.1111/jphp.12303

6. Zervas E, Samitas K, Gaga M. Assessment of satisfaction with 
different dry powder inhalation devices in Greek patients with COPD and asthma: the ANASA study. Int J Chron Obstruct Pulmon Dis. 2016;11:1845-1855. doi:10.2147/COPD.S113870

7. Karampitsakos T, Hillas G, Zervas E, et al. Prospective evAluatlon foR inhalation devices in Greek patients with COPD and asthma: The PAIR study. Pulm Pharmacol Ther. 2020;60:101882. doi:10.1016/j.pupt.2019.101882

8. Bouros D, Evangeliou MN. Critical Steps: A NonInterventional, Multicenter, Prospective, Observational Study on Critical Handling Errors with DPI Use, Asthma and COPD Patients. J Pulm Respir Med. 2016;6(4):1000360. doi:10.4172/2161-105X.1000360

9. Bakakos P, Papakosta D, Loukides S. Budesonide/formoterol via the Elpenhaler ${ }^{\circledR}$ device [BOREAS study] in asthmatic patients: A real-world effectiveness study. Pneumon. 2021;34(4):22. doi:10.18332/pne/144485

10. Juniper EF, O'Byrne PM, Guyatt GH, Ferrie PJ, King DR. Development and validation of a questionnaire to measure asthma control. Eur Respir J. 1999;14(4):902-907. doi:10.1034/j.1399-3003.1999.14d29.x

11. Juniper EF, Guyatt GH, Willan A, Griffith LE. Determining a minimal important change in a disease-specific Quality of Life Questionnaire. J Clin Epidemiol. 1994;47(1):81-87. doi:10.1016/0895-4356(94)90036-1

12. Brown T, Jones T, Gove K, et al. Randomised controlled trials in severe asthma: selection by phenotype or stereotype. Eur Respir J. 2018;52(6):1801444. doi:10.1183/13993003.01444-2018

13. Wechsler ME, Kelley JM, Boyd IOE, et al. Active albuterol or placebo, sham acupuncture, or no intervention in asthma. N Engl J Med. 2011;365(2):119-126. doi:10.1056/NEJMoa1103319 